\title{
Interspecific sensitivity of European amphibians towards two pesticides and comparison to standard test species
}

\author{
Elena Adams ${ }^{1,2^{*}}$ (D), Christoph Leeb ${ }^{1}$, Alexis P. Roodt ${ }^{1}$ and Carsten A. Brühl ${ }^{1}$
}

\begin{abstract}
Background: Although debates about the assessment of potential effects of pesticides on amphibians are ongoing, amphibians are not yet considered in the current EU environmental risk assessment of pesticides. Instead, the risk assessment of potential effects on aquatic amphibian life stages relies on use of data of surrogate species like the standard temperate fish species rainbow trout (Oncorhynchus mykiss). This assumption is mainly based on the comparison to amphibian species not native to Europe such as the aquatic African clawed frog (Xenopus laevis). It remains unclear whether these surrogate species cover semi-aquatic Central European amphibian sensitivities. Therefore, we assessed the acute sensitivity of aquatic stages of eight European amphibian species native in Germany (Bufo bufo, Bufotes viridis, Epidalea calamita, Hyla arborea, Pelobates fuscus, Pelophylax sp., Rana dalmatina, R. temporaria) towards commercial formulations of the fungicide folpet (Folpan ${ }^{\circledR} 500$ SC, Adama) and the insecticide indoxacarb (Avaunt ${ }^{\circledR}$ EC, Cheminova). The determined acute sensitivities (median lethal concentration, LC50) were included in species sensitivity distributions and compared to experimentally determined LC50 values of X. laevis and literature values of $O$. mykiss.
\end{abstract}

Results: The results showed that native amphibian sensitivities differed between the tested pesticides with a factor of 5 and 11. Depending on the pesticide, X. laevis was five and nine times more tolerant than the most sensitive native amphibian species. Comparing literature values of $O$. mykiss to the experimentally determined sensitivities of the native amphibian species showed that the $O$. mykiss sensitivity was in the same range as for the tested amphibians for the formulation Folpan ${ }^{\circledR} 500$ SC. The comparison of sensitivities towards the formulation Avaunt ${ }^{\circledR}$ EC showed an eight times lower sensitivity of $O$. mykiss than the most sensitive amphibian species.

Conclusions: A risk assessment using the 96-h LC50 values for fish covers the risk for the assessed aquatic stages of European amphibians after the application of the recommended uncertainty factor of 100 and thus may be adequate for lower tier risk assessment of the studied pesticides. If aquatic amphibian testing will be required for pesticide risk assessment nevertheless, acute tests with the model organism X. laevis and the application of an appropriate uncertainty factor might be a promising approach.

Keywords: Aquatic toxicity, Species sensitivity distribution, Oncorhynchus mykiss, Fungicide, Insecticide, Viticulture

*Correspondence: adams@uni-landau.de

1 iES Landau, Institute for Environmental Sciences, University of KoblenzLandau, Fortstraße 7, 76829 Landau, Germany

Full list of author information is available at the end of the article

\section{Background}

Latest reports of the International Union for the Conservation of Nature [24] suggest that $41 \%$ of all amphibian species are threatened. In the EU, 21 of 89 amphibian species are listed as critically endangered, endangered, or vulnerable for their global conservation status. Next to habitat loss and fragmentation, 
diseases, and climate change, exposure to anthropogenic pollutants such as agrochemicals is hypothesized to be one of the main causes of amphibian decline [10, 36]. Although debates about the assessment of potential effects of pesticides on amphibians are ongoing, amphibians are not yet considered in the current EU environmental risk assessment (ERA) of pesticides. Currently, the risk assessment of potential effects on aquatic amphibian life stages relies on use of data of standard test organisms such as fish [27]. Therefore, it is important to assess the sensitivity of amphibians to pesticides and compare their sensitivity to other taxa such as the standard test species rainbow trout (Oncorhynchus mykiss). Several meta-studies and critical reviews have already compared the sensitivities of larval amphibian stages and fish to environmental toxicants. For example, Birge et al. [7], Fryday and Thompson [16] and Weltje et al. [37] determined in general lower sensitivities of amphibians than fish. However, the majority of these comparisons is based on pesticides that are no longer commonly used in the EU (e.g., DDT, atrazine, carbaryl or chlorinated pesticides like chlorpyrifos and lindane). Moreover, many of these studies focus on model species not native to Europe such as North American species or (sub-) tropical species like the African clawed frog (Xenopus laevis). X. laevis is often used as model species for amphibians $[5,20]$ because it is easy to culture and handle in laboratory and there is a wide knowledge of its developmental biology [14]. However, there are few comparative toxicity data for $X$. laevis relative to other amphibian species. Several studies have found that $X$. laevis is more tolerant to environmental pollutants than other amphibian species [7, 20,30]. In addition, the European common frog (Rana temporaria) was described as more sensitive than O. mykiss and X. lae$v i$ towards heavy metals and industrial effluents [7]. It remains unclear whether the sensitivity of tadpoles of the aquatic species $X$. laevis to pesticides is also protective for semi-aquatic species native in Europe [27].

These shortcomings question the assumption that standard test species such as $O$. mykiss and X. laevis might be protective surrogates also for Central European amphibian species. Therefore, the aim of the present study was (i) to assess the sensitivity of larvae of eight native Central European species towards commercial formulations of the two pesticides folpet and indoxacarb and (ii) to compare the sensitivity of these native species with the sensitivity of $X$. laevis using experimentally derived sensitivities of $X$. laevis, and to the sensitivity of $O$. mykiss using values from the literature.

\section{Material and methods}

\section{Pesticide formulations}

The tests were performed with commercial formulations of the viticulturally used fungicide folpet (Folpan ${ }^{\circledR}$ 500 SC, 38-42\% a.i., hereafter Folpan) and insecticide indoxacarb (Avaunt ${ }^{\circledR}$ EC, $15.84 \%$ a.i., hereafter Avaunt). Viticulture is one of the most pesticide-intensive cultures in Central Europe and both pesticides are the most common German viticultural fungicide and insecticide, respectively [35]. Formulations were used instead of technical grade active ingredients because it represents a more realistic scenario as non-target organisms such as amphibians are exposed to these products, not merely to active ingredients. Moreover, previous studies showed that formulation co-formulants may affect the toxicity to amphibians [8, 32].

Folpet is an organochlorine phthalimide and used as a protective, broad-spectrum fungicide against leaf spot diseases in grapevines. The acute aquatic toxicity leads to 96-h LC50 values of $0.233 \mathrm{mg}$ folpet/L [4] and $0.256 \mathrm{mg}$ Folpan/L for O. mykiss [1]. The oxadiazine indoxacarb is effective against early life stages of Lepidoptera, Orthoptera, Hemiptera and Coleoptera via contact or ingestion with a 96-h LC50 >0.17 mg indoxacarb/L [4]] and $7.0 \mathrm{mg}$ Avaunt/L for O. mykiss [9].

\section{Test species}

In total, nine amphibian species were tested. Besides the standard laboratory species X. laevis (Daudin, 1802), we investigated the Central European native species common toad Bufo bufo (Linnaeus, 1758), green toad Bufotes viridis (Laurenti, 1768), natterjack toad Epidalea calamita (Laurenti, 1864), common tree frog Hyla arborea (Linnaeus, 1758), common spadefoot toad Pelobates fuscus (Laurenti, 1768), water frog Pelophylax sp. (Fitzinger, 1843), agile frog Rana dalmatina (Fitzinger, 1839), and common frog Rana temporaria (Linnaeus, 1758). Between April 2018 and May 2019, parts of three to five egg clutches of each native test species except for E. calamita were collected from breeding ponds in South Germany (Additional file 1: Table S1). E. calamita individuals were found only as early hatched tadpoles. Native species were collected from non-agricultural breeding ponds to reduce the potential of evolutionary adaption to pesticides [11, 23] except for B. viridis because no populations from non-agricultural sites were available. A definite differentiation between $P$. ridibundus, $P$. lessonae and the hybridized form of both (P. esculentus) was not possible. Thus, we refer to Pelophylax sp. as a water frog species. X. laevis were obtained from the in-house culture of Eurofins Agroscience Services EcoChem GmbH (Niefern-Öschelbronn, Germany). Information about the 
threat status and used habitats of the selected test species in Germany and Europe can be found in the supplementary material (Additional file 2: Table S2).

Housing and experiments were performed in a climate chamber (WK 19'/+15-35, Weiss Technik GmbH, Reiskirchen, Germany) with a 16:8-h light:dark rhythm at $21 \pm 1{ }^{\circ} \mathrm{C}$. The collected egg clutches were distributed to aerated $15-\mathrm{L}$ aquaria $(32 \times 24 \times 20 \mathrm{~cm})$ filled with FETAX medium [12]. Medium renewal took place every other day. Developmental stages were assigned according to Gosner [17] for native species and Nieuwkoop und Faber [26] for X. laevis. Native species were tested in the non-feeding, freshly hatched larval Gosner stage (GS) 20 because Adams and Brühl [2] showed higher sensitivity of GS20 in comparison to the commonly used GS25 of $R$. temporaria to the fungicide folpet. E. calamita had to be tested in the free-swimming GS25 because no embryos were found in nature and individuals had already developed to GS25 after the performance of range-finding tests. X. laevis was tested in the freshly hatched Nieuwkoop-Faber stage (NF) 41-45.

\section{Acute toxicity tests}

The study design was derived from the OECD TG 203 (Fish, Acute Toxicity Test; [29]) and TG 202 (Daphnia sp. Acute Immobilisation Test [28]). To provide guidance on the final test concentrations, 48-h range-finding tests with three concentrations of each pesticide formulation and a control group with three replicates of one individual were performed for each species. In the final tests, 96-h median lethal concentrations (LC50) of each species were determined in a static dose-response set-up with six concentrations (Table 1). Tests were conducted in $1.7 \mathrm{~L}$ glass jars filled with $1 \mathrm{~L}$ test solution prepared with FETAX medium. Per concentration, five replicates with five randomly chosen individuals were used resulting in 150 tadpoles per test. No feeding took place during the tests and dead tadpoles were removed every $24 \mathrm{~h}$. After $96 \mathrm{~h}$, the experiments were terminated, mortality was determined, and all surviving tadpoles were euthanized with a $0.1 \%$ buffered MS-222 solution. Concentrations at the beginning of the test and at test termination were analysed for indoxacarb $(n=9$, Additional file 3$)$. Due to the rapid degradation of folpet in aquatic environments $(\mathrm{DT} 50=1.2 \mathrm{~h}$ at $\mathrm{pH} 7, \mathrm{DT} 50=1 \mathrm{~min}$ at $\mathrm{pH}$ 9; values extracted from Agriculture and Environment Research Unit of the University of Hertfordshire [4]), concentration measurements would have not increased the explanatory power of this study as no reliable concentrations would have been generated.

\section{Statistical analyses}

For statistical analyses the software $\mathrm{R}$ for Windows [33], Version 4.0.2) was used. The extension package "drc" [34] was used to fit a dose-response model for each amphibian species and pesticide formulation (Additional file 4:

Table 1 Intended test concentrations of Folpan (38-42\% folpet) and Avaunt (15.84\% indoxacarb) used in acute toxicity tests

\begin{tabular}{|c|c|c|c|c|c|c|c|}
\hline \multirow[t]{2}{*}{ Pesticide } & \multirow[t]{2}{*}{ Species } & \multicolumn{6}{|c|}{ Test concentration (mg formulation/L) } \\
\hline & & 1 & 2 & 3 & 4 & 5 & 6 \\
\hline \multirow[t]{9}{*}{ Folpan } & Bufo bufo & 0 & 1.0 & 1.5 & 2.0 & 2.5 & 3.0 \\
\hline & Bufotes viridis & 0 & 0.7 & 0.9 & 1.1 & 1.3 & 1.5 \\
\hline & Epidalea calamita & 0 & 0.5 & 1.0 & 1.5 & 2.0 & 2.5 \\
\hline & Hyla arborea & 0 & 1.5 & 1.7 & 1.9 & 2.1 & 2.3 \\
\hline & Pelobates fuscus & 0 & 1.2 & 1.3 & 1.4 & 1.5 & 1.6 \\
\hline & Pelophylax sp. & 0 & 0.3 & 0.4 & 0.5 & 0.6 & 0.7 \\
\hline & Rana dalmatina & 0 & 1.2 & 1.5 & 1.8 & 2.1 & 2.4 \\
\hline & Rana temporaria & 0 & 0.4 & 0.5 & 0.6 & 0.7 & 0.8 \\
\hline & Xenopus laevis & 0 & 1.4 & 1.7 & 2.0 & 2.3 & 2.6 \\
\hline \multirow[t]{9}{*}{ Avaunt } & Bufo bufo & 0 & 0.4 & 0.6 & 0.8 & 1.0 & 1.2 \\
\hline & Bufotes viridis & 0 & 2.0 & 2.5 & 3.0 & 3.5 & 4.0 \\
\hline & Epidalea calamita & 0 & 1.0 & 1.2 & 1.4 & 1.6 & 1.8 \\
\hline & Hyla arborea & 0 & 2.0 & 2.5 & 3.0 & 3.5 & 4.0 \\
\hline & Pelobatesfuscus & 0 & 2.5 & 3.0 & 3.5 & 4.0 & 4.5 \\
\hline & Pelophylax sp. & 0 & 8.8 & 9.0 & 9.2 & 9.4 & 9.6 \\
\hline & Rana dalmatina & 0 & 2.2 & 2.5 & 2.8 & 3.1 & 3.4 \\
\hline & Rana temporaria & 0 & 1.5 & 2.0 & 2.5 & 3.0 & 3.5 \\
\hline & Xenopus laevis & 0 & 7.0 & 7.2 & 7.4 & 7.6 & 7.8 \\
\hline
\end{tabular}


Table S3). Candidate models were log-normal functions (LN.2, LN.3, LN.4), log-logistic functions (LL.2, LL.3u, LL.4, LL.5), and Weibull-functions (W1.2, W1.3, W1.4, W2.2, W2.3, W2.4). Models were selected by using Akaike information criterion (AIC). Afterwards, LC50 values were calculated for each species and formulation. All amphibian species were ordered from most to least sensitive towards the pesticide formulations and pairwise comparisons via LC50 ratio test after Bonferroni correction [38] were performed to assess significant differences in sensitivity between species. If 95\% lower and upper confidence intervals of the calculated differences did not include zero, the differences were judged statistically significant (Additional file 5: Table S4).

\section{Generation of species sensitivity distributions and derivation of risk assessment parameters}

Species sensitivity distributions (SSDs) can be used as an ecotoxicological tool for the derivation of quality criteria in ERA. They represent the variation in species sensitivities to a specific contaminant by a statistical distribution function of responses for a sample of species [31]. SSDs were computed with the package "fitdistrplus" [13] for both formulations using the 96-h LC50 values of the European amphibian species to compare their sensitivities. By fitting a suitable statistical distribution to the data, the concentration at which $5 \%$ of species were affected by the formulations (HC5, hazard concentration) was derived as the 5th percentile of the SSDs [31]. To determine whether $O$. mykiss and X. laevis are suitable surrogate species for European amphibians, the 96-h LC50 literature values for $O$. mykiss and the determined 96-h LC50 values for X. laevis were compared to the European amphibian. Moreover, regulatory acceptable concentrations (RACs) which are determined in the current tier 1 risk assessment for fish by dividing their LC50 values by an assessment factor of 100 were compared to the calculated HC5 values derived from the native amphibian SSDs.

\section{Results}

\section{Amphibian sensitivities}

No mortality was observed in any of the control groups. Sensitivity towards the pesticide formulation Folpan varied between all tested amphibian species in the decreasing order Pelophylax sp.>Rana temporaria $>$ Bufotes viridis $=$ Epidalea calamita $=$ Pelobates fuscus $>$ Hyla arborea $>$ Rana dalmatina $=$ Xenopus laevis $=$ Bufo bufo ("> " denotes significant difference, "=" denotes no difference; Additional file 5: Table S4). Native amphibian sensitivities ranged from 0.44 to $2.19 \mathrm{mg}$ Folpan/L with a sensitivity range of a factor of five (Fig. 1, Table 2). The

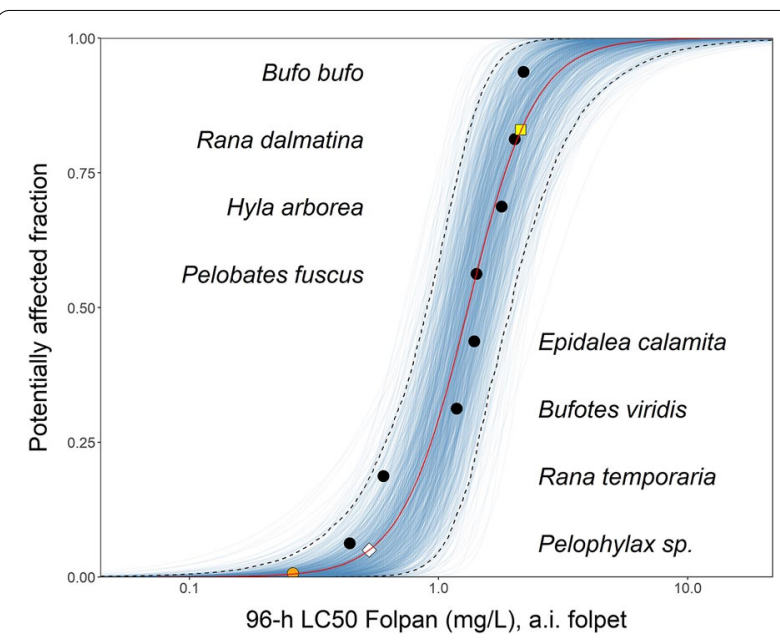

Fig. 1 Species sensitivity distribution of Folpan (38-42\% a.i. folpet) calculated from European amphibian sensitivities (red line). Black filled circles denote 96-h LC50 values of European amphibian species. For better comparison, the determined $96-h$ LC50 values of Xenopus laevis (yellow filled square) and the 96-h LC50 literature value of Oncorhynchus mykiss (orange filled circle) were included for the formulation Folpan. Species names are aligned in ascending order from bottom to top on the same $y$-axis coordinate as their respective $L C 50$ value. Dashed lines represent parametric bootstrap $95 \%$ confidence intervals (1000 iterations) of native amphibian species. Blue lines display all parametric bootstrap samples of native amphibian species. White filled diamond marks the HC5 value for native amphibian species

Table 2 Formulation LC50 values of studied amphibian species and literature LC50 values of Oncorhynchus mykiss

\begin{tabular}{lll}
\hline Species & Folpan LC50 [mg/L] & $\begin{array}{l}\text { Avaunt } \\
\text { LC50 } \\
\text { [mg/L] }\end{array}$ \\
\hline Bufo bufo & & 0.86 \\
Bufotes viridis & 2.19 & 2.62 \\
Epidalea calamita & 1.18 & 1.26 \\
Hyla arborea & 1.39 & 2.43 \\
Pelobates fuscus & 1.79 & 3.31 \\
Pelophylax sp. & 1.42 & 9.43 \\
Rana dalmatina & 0.44 & 2.26 \\
Rana temporaria & 2.02 & 2.50 \\
Xenopus laevis & 0.60 & 7.59 \\
Oncorhynchus mykiss & 2.14 & 7.0 \\
\hline
\end{tabular}

HC5 of Folpan for European amphibians was determined to be $0.52 \mathrm{mg}$ Folpan/L.

Sensitivities towards Avaunt decreased in the order Bufo bufo $>$ Epidalea calamita $>$ Rana dalmatina $>$ Hyla arborea $=$ Rana temporaria $=$ Bufotes viridis $>$ Pelobates fuscus $>$ Xenopus laevis $>$ Pelophylax sp. and ranged from 0.86 to $9.43 \mathrm{mg}$ Avaunt/L, thus revealing 11-fold 


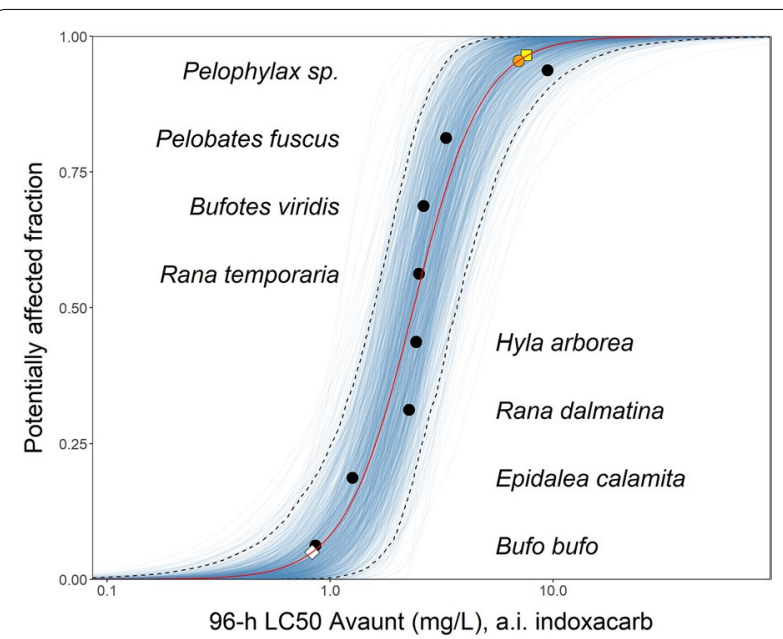

Fig. 2 Species sensitivity distribution of Avaunt (15.84\% a.i. indoxacarb) calculated from European amphibian sensitivities (red line). Black filled circles denote 96-h LC50 values of European amphibian species. For better comparison, the determined $96-\mathrm{h}$ LC50 values of Xenopus laevis (yellow filled square) and the 96-h LC50 literature value of Oncorhynchus mykiss (orange filled circle) were included for the formulation Avaunt. Species names are aligned in ascending order from bottom to top on the same $y$-axis coordinate as their respective LC50 value. Dashed lines represent parametric bootstrap 95\% confidence intervals (1000 iterations) of native amphibian species. Blue lines display all parametric bootstrap samples of native amphibian species. White filled diamond marks the HC5 value for native amphibian species

sensitivity differences (Fig. 2, Table 2). The SSD of Avaunt revealed a $\mathrm{HC} 5$ of $0.83 \mathrm{mg}$ Avaunt/L.

\section{Comparison of European amphibians to O. mykiss and $X$. laevis}

Xenopus laevis was the second most tolerant species towards Folpan with a nearly five times lower sensitivity than the most sensitive amphibian species Pelophylax sp. O. mykiss showed the highest sensitivity towards Folpan $(0.256 \mathrm{mg}$ Folpan/L) with a 1.8-fold higher sensitivity than Pelophylax sp. For the formulation Avaunt, X. laevis was the second most tolerant amphibian species with a nearly nine times lower sensitivity than the most sensitive species B. bufo. The formulation LC50 of $7.0 \mathrm{mg}$ Avaunt/L for O. mykiss leads to the second lowest sensitivity with an 8.1-fold lower sensitivity than the most sensitive amphibian species $B$. bufo.

\section{Discussion}

Suitability of standard test species like O. mykiss and the model amphibian species $X$. laevis as surrogate species for European native amphibian species was questioned by EFSA [27]. For interpretation of the results, it needs to be taken into account that only one population of each species was investigated, thus representing limited genetic variability. Moreover, individuals were collected from natural ponds. Thus, exposure and adaptation to potentially present pesticides cannot be excluded. Because $B$. viridis embryos were collected from an agricultural pond, tadpoles might have been less sensitive than individuals from non-agricultural sites [11, 23]. As the water frog species was not identifiable definitely, our study might not cover sensitivity variations within the water frog species complex. It further needs to be mentioned that $E$. calamita was the only species tested in the feeding stage GS25. However, sensitivity differences to earlier stages are expected to be in the same range because $R$. temporaria tadpoles in GS20 showed a LC50 of $1.01 \mathrm{mg} / \mathrm{L}$ and tadpoles in GS25 a LC50 of $1.22 \mathrm{mg} / \mathrm{L}$ for a folpet formulation [2]. Therefore, we expected sensitivity differences between GS20 and GS25 for E. calamita to be neglectable compared to differences to other species and decided to consider the sensitivities of E. calamita in our comparisons. However, as stage dependent toxicity such as potential starvation stress might occur, the results for E. calamita need to be considered with caution.

Our study shows that no general conclusion can be drawn for amphibian sensitivity differences and the use of surrogate species for all pesticide classes because amphibian sensitivities varied between the tested pesticides with 5- to 11-fold differences. The detected sensitivity differences may be due to different modes of action and physiological properties of the species because the fungicide folpet acts as cell division inhibitor of many microorganisms with a multi-site activity [4] whereas the insecticide indoxacarb is a sodium channel blocker that acts via contact and stomach action [4]. Interestingly, the most sensitive species towards Folpan Pelophylax sp. was the least sensitive species towards Avaunt. On the other hand, $B$. bufo was the most sensitive species towards Avaunt but the least sensitive species towards Folpan indicating a complete reversal of these two species in sensitivity. Also other studies found contrasting results. Harris et al. [19] observed a lower sensitivity of B. americanus embryos towards the fungicide mancozeb than $R$. pipiens embryos, but reverse results for the insecticide endosulfan. These different results show that amphibian sensitivity differences cannot be defined only by family or pesticide class.

In the present study, X. laevis was five to nine times more tolerant than the most native amphibian species. In contrast to our results, comparisons of the sensitivities of $X$. laevis to Pelophylax ridibundus revealed $X$. laevis tadpoles to be more sensitive towards the insecticide methidathion and the herbicide glyphosate [18]. However, based on our findings, X. laevis can be used as surrogate for acute risk assessments of Central European aquatic amphibian stages when applying 
a minimum uncertainty factor of at least 9 that covers higher sensitivities of the tested native species.

Sensitivity of O. mykiss towards Folpan seems to be in the same range as for the tested amphibian species thus indicating a suitable surrogate for aquatic stages of European amphibian species. The LC50 of $7.0 \mathrm{mg}$ Avaunt/L for O. mykiss indicates an 8.1-fold lower sensitivity than the most sensitive species B. bufo. Assuming an aquatic tier 1 risk assessment, the recommended uncertainty factor of 100 for fish acute toxicity tests [15] leads to RACs of $2.56 \times 10^{-3} \mathrm{mg}$ Folpan/L and $0.07 \mathrm{mg}$ Avaunt/L. These RACs would cover the sensitivity of all tested amphibian species. They also cover the determined HC5 values which are 200 and 12 times higher than the determined RACs. Thus, considering the assessment factor of 100 which is used in the tier 1 risk assessment, the assumption of Birge et al. [7], Fryday und Thompson [16], and Weltje et al. [37] that acute toxicity data of standard fish species (here $O$. mykiss) are suitable to cover the sensitivity of aquatic amphibian stages was confirmed for the investigated European amphibian species in an early hatchling stage for two current-use pesticides. It needs to be noted that all tests were carried out under laboratory conditions at stable temperatures of $21{ }^{\circ} \mathrm{C}$. Temperature and other environmental conditions are co-stressors which might change the amphibian sensitivity [6,25]. Additionally, it remains unclear whether fish and amphibians are similarly sensitive to formulation co-formulants [21, 22]. Especially terrestrial stages seem to be very sensitive to co-formulants in formulations $[3,8]$ which might be particularly toxic to the permeable skin of terrestrial amphibians.

\section{Conclusions}

For the first time the present study assessed aquatic sensitivity differences of Central European amphibian species in comparison to standard test organisms such as $O$. mykiss and X. laevis. The results of our study support the notion of preceding reviews that acute toxicity data generated using standard aquatic test species meet the requirements for acute aquatic amphibian risk assessment after the application of the assessment factor of 100. If aquatic amphibian testing will be required for pesticide risk assessment nevertheless, test methods with the model organism $X$. laevis considering the application of a reliable uncertainty factor might be a promising approach. Substantial research on interaction of temperature and pesticide stress, formulation and terrestrial toxicity is still necessary to derive standardized acute toxicity tests and a protective ERA for amphibians.

\section{Abbreviations}

a.i.: Active ingredient; DT: Dissipation time; ERA: Environmental risk assessment; EU: European Union; HC: Hazard concentration; IUCN: International Union for the Conservation of Nature; LC: Lethal concentration; SSD: Species sensitivity distribution.

\section{Supplementary Information}

The online version contains supplementary material available at https://doi. org/10.1186/s12302-021-00491-1.

Additional file 1: Table S1. Withdrawal locations of studied European test species.

Additional file 2: Table S2. Artificial terrestrial and aquatic habitats of examined amphibian species.

Additional file 3: SI Document 1. Pesticide residue analysis.

Additional file 4: Table S3. Model specification on which each 96-h LC50 value is based.

Additional file 5: Table S4. Contingency table of estimated difference of LC50 via Cl ratio testing.

\section{Acknowledgements}

We thank Haiying Xia for her laboratory assistance and Philipp Uhl for his support in the statistical analyses. The authors are grateful for the provision of Xenopus laevis embryos by Valentin Mingo of Eurofins Agroscience Services EcoChem $\mathrm{GmbH}$.

\section{Authors' contributions}

EA: conceptualization, methodology, investigation, formal analysis, writing-original draft preparation. CL: conceptualization, writing-reviewing and editing. APR: pesticide residue analysis, writing — reviewing and editing. CAB: conceptualization, writing — reviewing and editing. All authors read and approved the final manuscript.

\section{Funding}

Open Access funding enabled and organized by Projekt DEAL. EA was financed by the Ph.D. scholarship program of the German Federal Environmental Foundation. CL was financed by the Deutsche Forschungsgesellschaft (DFG-TH 1807-2).

\section{Availability of data and materials}

The datasets used and/or analysed during the current study are available from the corresponding author on reasonable request.

\section{Declarations}

\section{Ethics approval and consent to participate}

The experiments and withdrawal of animals were approved by the Federal Investigation Office (Landesuntersuchungsamt, Koblenz, Germany) to § 8a of the German law for animal welfare (license number 23 177-07/G18-20-009), the Struktur- und Genehmigungsdirektion Süd (Neustadt an der Weinstraße, Germany, license number 42/553-254/455-18) and the Regierung der Oberpfalz (Regensburg, license number ROP-SG55.1-8646.4-1-1115-3).

\section{Consent for publication \\ Not applicable.}

\section{Competing interests}

EA is involved in the private sector. However, the conceptualization, methodology and formal analysis of the present paper were performed when all authors were affiliated with the University of Koblenz-Landau. Therefore, we see no conflict of interest arising from this involvement for the present submission.

\section{Author details}

${ }^{1}$ iES Landau, Institute for Environmental Sciences, University of KoblenzLandau, Fortstraße 7, 76829 Landau, Germany. ${ }^{2}$ Present Address: Crop 
Science Division, Research \& Development, Environmental Safety, Bayer AG, Alfred-Nobel-Straße 50, 40789 Monheim, Germany.

\section{Received: 24 January 2021 Accepted: 29 March 2021}

Published online: 18 April 2021

\section{References}

1. Adama (2015) Safety data sheet according to regulation (EC) No. 1907/2006 (REACH) - Product Number FNG56820-A (Folpan 500 SC)

2. Adams E, Brühl CA (2020) Fungicide exposure induces sensitivity differences in aquatic life stages of European common frogs (Rana temporaria). J Herpetol. https://doi.org/10.1670/19-004

3. Adams E, Gerstle V, Brühl CA (2020) Dermal fungicide exposure at realistic field rates induces lethal and sublethal effects on Juvenile European common frogs (Rana temporaria). Environ Toxicol Chem. https://doi.org/ 10.1002/etc.4972

4. Agriculture and Environment Research Unit of the University of Hertfordshire (2013) The Pesticide Properties DataBase

5. Aldrich A (2009) Sensitivity of amphibians to pesticides: Empfindlichkeit von Amphibien gegenüber Pflanzenschutzmitteln. AGRARForschung 16:466-471

6. Baier F, Jedinger M, Gruber E, Zaller JG (2016) Temperature-dependence of glyphosate-based herbicide's effects on egg and tadpole growth of common toads. Front Environ Sci 4:281. https://doi.org/10.3389/fenvs. 2016.00051

7. Birge WJ, Black JA, Westerman AG (1985) Short-term fish and amphibian embryo-larval tests for determining the effects of toxicant stress on early life stages and estimating chronic values for single compounds and complex effluents: complex mixtures. Environ Toxicol Chem 4:807-821. https://doi.org/10.1002/etc.5620040612

8. Brühl CA, Schmidt T, Pieper S, Alscher A (2013) Terrestrial pesticide exposure of amphibians: an underestimated cause of global decline? Sci Rep 3:1135. https://doi.org/10.1038/srep01135

9. Cheminova (2020) Safety data sheet according to regulation (EC) No. 1907/2006 (REACH) - Avaunt: FMC Agricultural Solutions

10. Collins JP, Storfer A (2003) Global amphibian declines: sorting the hypotheses. Divers Distrib 9:89-98. https://doi.org/10.1046/j.1472-4642.2003. 00012.x

11. Cothran RD, Brown JM, Relyea RA (2013) Proximity to agriculture is correlated with pesticide tolerance: evidence for the evolution of amphibian resistance to modern pesticides. Evol Appl 6:832-841. https://doi.org/10. 1111/eva.12069

12. Dawson DA, Bantle JA (1987) Development of a reconstituted water medium and preliminary validation of the frog embryo teratogenesis assay-Xenopus (FETAX). J Appl Toxicol 7:237-244. https://doi.org/10.1002/ jat.2550070403

13. Delignette-Muller ML, Pouillot R, Denis J-B, Dutang C (2014) fitdistrplus: help to fit of a parametric distribution to non-censored or censored data. http://CRAN.R-project.org/package=fitdistrplus/

14. Deuchar EM (1972) Xenopus laevis and developmental biology. Biol Rev 47:37-112. https://doi.org/10.1111/j.1469-185X.1972.tb00970.x

15. EFSA PPR Panel (2013) Guidance on tiered risk assessment for plant protection products for aquatic organisms in edge-of-field surface waters. EFSA. 11:268

16. Fryday S, Thompson $\mathrm{H}$ (2012) Toxicity of pesticides to aquatic and terrestrial life stages of amphibians and occurrence, habitat use and exposure of amphibian species in agricultural environments. EFSA 9:22. https://doi. org/10.2903/sp.efsa.2012.EN-343

17. Gosner KL (1960) Simplified table for staging anuran embryos and larvae with notes on identification. Herpetologica 16:183-190

18. Güngördü A (2013) Comparative toxicity of methidathion and glyphosate on early life stages of three amphibian species: Pelophylax ridibundus, Pseudepidalea viridis, and Xenopus laevis. Aquat Toxicol 140-141:220-228. https://doi.org/10.1016/j.aquatox.2013.06.012

19. Harris ML, Chora L, Bishop CA, Bogart JP (2000) Species- and age-related differences in susceptibility to pesticide exposure for two amphibians, Rana pipiens, and Bufo americanus. Bull Environ Contam Toxicol 64:263-270. https://doi.org/10.1007/s001289910039
20. Hoke RA, Ankley GT (2005) Application of frog embryo teratogenesis assay-Xenopus to ecological risk assessment. Environ Toxicol Chem 24:2677-2690. https://doi.org/10.1897/04-506R.1

21. Hooser EA, Belden JB, Smith LM, McMurry ST (2012) Acute toxicity of three strobilurin fungicide formulations and their active ingredients to tadpoles. Ecotoxicology 21:1458-1464. https://doi.org/10.1007/ s10646-012-0899-y

22. Howe CM, Berrill M, Pauli BD, Helbing CC, Werry K, Veldhoen N (2004) Toxicity of glyphosate-based pesticides to four North American frog species. Environ Toxicol Chem 23:1928-1938. https://doi.org/10.1897/03-71

23. Hua J, Morehouse NI, Relyea R (2013) Pesticide tolerance in amphibians: induced tolerance in susceptible populations, constitutive tolerance in tolerant populations. Evol Appl 6:1028-1040. https://doi.org/10.1111/eva. 12083

24. IUCN (2020) The IUCN Red List of Threatened Species. Version 2020-1. https://www.iucnredlist.org. Accessed 2 June 2020

25. Mikó Z, Ujszegi J, Gál Z, Imrei Z, Hettyey A (2015) Choice of experimental venue matters in ecotoxicology studies: comparison of a laboratorybased and an outdoor mesocosm experiment. Aquat Toxicol 167:20-30. https://doi.org/10.1016/j.aquatox.2015.07.014

26. Nieuwkoop PD, Faber J (1994) Normal table of Xenopus laevis (Daudin): a systematical and chronological survey of the development from the fertilized egg till the end of metamorphosis. Garland Publishing Inc, New York

27. Ockleford C, Adriaanse P, Berny P, Brock T, Duquesne S, Grilli S, HernandezJerez AF, Bennekou SH, Klein M, KuhI T, Laskowski R, Machera K, Pelkonen O, Pieper S, Stemmer M, Sundh I, Teodorovic I, Tiktak A, Topping CJ, Wolterink G, Aldrich A, Berg C, Ortiz-Santaliestra M, Weir S, Streissl F, Smith $\mathrm{RH}$ (2018) Scientific Opinion on the state of the science on pesticide risk assessment for amphibians and reptiles. EFSA. 16:466. https://doi.org/10. 2903/j.efsa.2018.5125

28. OECD (2004) TG 202: Daphnia sp Acute Immobilisation Test: OECD Guidelines for the Testing of Chemicals Section 2. OECD, Paris

29. OECD (2019) TG 203: Fish, Acute Toxicity Test: OECD Guidelines for the Testing of Chemicals, Section 2. OECD, Paris

30. Ortiz-Santaliestra ME, Maia JP, Egea-Serrano A, Lopes I (2018) Validity of fish, birds and mammals as surrogates for amphibians and reptiles in pesticide toxicity assessment. Ecotoxicology 27:819-833. https://doi.org/ 10.1007/s10646-018-1911-y

31. Posthuma L, Suter GW, Traas TP (eds) (2001) Species sensitivity distributions in ecotoxicology. Environmental and ecological risk assessment. Lewis Publishers, Boca Ratón

32. Puglis HJ, Boone MD (2011) Effects of technical-grade active ingredient vs. commercial formulation of seven pesticides in the presence or absence of UV radiation on survival of green frog tadpoles. Arch Environ Contam Toxicol 60:145-155. https://doi.org/10.1007/s00244-010-9528-z

33. R Core Team (2020) R: A language and environment for statistical computing. www.R-project.org

34. Ritz C, Streibig JC (2005) Bioassay analysis using R. J Stat Soft. https://doi. org/10.18637/jss.v012.i05

35. Roßberg D, Ipach R (2015) Erhebungen zur Anwendung von Pflanzenschutzmitteln im Weinbau. J Kult. https://doi.org/10.5073/JFK.2015.12.03

36. Stuart SN, Chanson JS, Cox NA, Young BE, Rodrigues ASL, Fischman DL, Waller RW (2004) Status and trends of amphibian declines and extinctions worldwide. Science 306:1783-1786. https://doi.org/10.1126/scien ce. 1103538

37. Weltje L, Simpson P, Gross M, Crane M, Wheeler JR (2013) Comparative acute and chronic sensitivity of fish and amphibians: a critical review of data. Environ Toxicol Chem 32:984-994. https://doi.org/10.1002/etc.2149

38. Wheeler MW, Park RM, Bailer AJ (2006) Comparing median lethal concentration values using confidence interval overlap or ratio tests. Environ Toxicol Chem 25:1441-1444. https://doi.org/10.1897/05-320R.1

\section{Publisher's Note}

Springer Nature remains neutral with regard to jurisdictional claims in published maps and institutional affiliations. 